\title{
Mobilidade urbana na perspectiva das mulheres: hacktivismo no mapeamento de assédio em transportes públicos
}

\author{
Simony C. R. de Moura ${ }^{1}$, Jucylene H. A. de Melo ${ }^{2}$ \\ ${ }^{1}$ Departamento de Design Gráfico - Instituto Federal de Educação, Ciência e Tecnologia \\ da Paraíba (IFPB) \\ Rua Santa Rita de Cássia, 1900 - Jardim Camboinha, Cabedelo - PB, 58103-772 \\ ${ }^{2}$ Departamento de Computação e Tecnologia - Universidade Federal do Rio Grande do \\ Norte (UFRN) - Caicó, RN - Brazil \\ simonycesarr@gmail.com, jucylenemelo@gmail.com
}

\begin{abstract}
A programming marathon results in the emergence of a collaborative initiative between Information Technology women and Design women, which the mean objective is create a social media for tracking the harassment complaint in public transportation. A social network of feminist, called Nina. With the sharing and storage of such data, the portal will be fed and mapped the main harassment cases, identifying bus lines which have the highest crime rate, the time, the routes, and other information. The big data collected will build the violence against women mapping in public transportation, which could become a platform of social pressure against the government to ask for measures to combat gender violence in urban mobility.
\end{abstract}

Resumo. Uma maratona de programação resulta no surgimento de uma iniciativa colaborativa entre mulheres de Tecnologia da Informação e Design que tem como intuito criar uma rede social para o rastreamento da denúncia de assédio em transportes públicos. Uma rede social feminista, a rede Nina. Com o compartilhamento e armazenagem de dados, o portal será alimentado e mapeará os principais casos de assédio identificando as linhas de ônibus que têm maior índice de crime, o horário, rotas e outras informações. Os dados livres coletados constroem o mapeamento de assédios e podem se tornar uma plataforma de pressão social contra o poder público no sentido de cobrar medidas de combate à violência de gênero na mobilidade urbana.

\section{Introdução}

"Cidades inteligentes" tem sido um termo recorrente nas discussões sobre o desenvolvimento das políticas de crescimento urbano. Estão os desafios complexos das cidades distantes do que se entende como qualidade de vida. Tal problemática ascende e alavanca a questão de: como a administração pública pode construir estratégias para solucionar problemas sociais fazendo uso de dados abertos? Ou como a sociedade civil 
pode ter acesso a dados e estudos e usá-los de maneira que pressione um posicionamento e uma ação efetiva e eficaz dos gestores públicos?

Hackers, ativistas digitais e todo o público que enxerga a internet como uma ferramenta poderosa começou a dar ainda mais atenção aos temas de transparência pública e democracia de acesso aos dados públicos. As redes horizontais de interação, especialmente as mídias sociais, propiciaram novas formas de comunicação, entre essas a autocomunicação de massa [CASTELLS 2009].

Acesso aos computadores... deve ser ilimitado e total... Todas as informações deveriam ser livres... Hackers desconfiam das autoridades e promovem a descentralização... Hackers devem ser julgados por seus "hackeamentos" e não por outros critérios, tais como escolaridade, idade, raça ou posição social... Você pode criar arte e beleza em um computador... Os computadores podem mudar sua vida para melhor. (LEVY, 2010, p. 28).

Cidades têm inúmeros problemas físicos, mas problemas humanos, comportamentais, como mapeá-los, como desconstrui-los? A Lei de Acesso à Informação (Lei 12527/2011) obriga órgãos públicos federais, estaduais e municipais (ministérios, estatais, governos estaduais, prefeituras, empresas públicas, autarquias) a ceder informações relacionadas às suas atividades a qualquer pessoa que solicitar tais informações. Nesse sentido, organizações público-privadas promoveram um hackathon ${ }^{1}$ que procurou estimular o uso de big data tendo como desafio o seu uso para desenvolver soluções que tivessem impacto nas cidades. Um dos dados dispostos na maratona de programação foi o dado de geolocalização da frota de ônibus da região metropolitana do Recife.

\section{A mobilidade urbana na perspectiva das mulheres}

A cada 11 minutos uma mulher é estuprada no Brasil. Mais de 5 por hora. 130 mulheres estupradas todos os dias. Apenas $10 \%$ dos casos chegam ao conhecimento da polícia, segundo o Fórum Brasileiro de Segurança Pública (2016).

Uma pesquisa ${ }^{2}$ divulgada (2016) pela ActionAid e realizada pelo instituto YouGov no Brasil, Índia, Tailândia e Reino Unido, ouviu 2.500 mulheres com idade acima de 16 anos nas principais cidades dos quatro países. No Brasil, foram pesquisadas 503 mulheres de todas as regiões do país. Todas as estudantes brasileiras participantes da pesquisa afirmaram que já foram assediadas em suas cidades. $86 \%$ das mulheres brasileiras ouvidas disseram já ter sofrido assédio em locais públicos. $\mathrm{O}$ levantamento evidencia que o assédio em espaços públicos é um problema global, visto que na Tailândia também $86 \%$ das mulheres entrevistadas, seguidas de $79 \%$ na Índia, e $75 \%$ na Inglaterra já viveram o mesmo problema de assédio.

\footnotetext{
${ }^{1}$ Hackathon significa maratona de programação. O termo resulta de uma combinação das palavras inglesas "hack" (programar de forma excepcional) e "marathon" (maratona).

2 Todos os resultados foram obtidos pelo YouGov. O tamanho total da amostra foi de 2.518 mulheres: 1.013 na Inglaterra, 503 no Brasil, 500 na Tailândia e 502 na Índia. O trabalho de campo foi realizado entre os dias 3 e 11 de maio de 2016. A pesquisa foi realizada online. Os números foram ponderados e são representativos de todas as mulheres maiores de idade em cada país. Para a pesquisa, foram considerados assédios atos indesejados, ameaçadores e agressivos contra as mulheres, podendo configurar abuso verbal, físico, sexual ou emocional. Fonte: ActionAid (actionaid.org.br)
} 
Em relação às formas de assédio sofridas em público pelas brasileiras, o assobio é o mais comum (77\%), seguido por olhares insistentes $(74 \%)$, comentários de cunho sexual $(57 \%)$ e xingamentos (39\%). Metade das mulheres entrevistadas no Brasil disse que já foram seguidas nas ruas, $44 \%$ tiveram seus corpos tocados, $37 \%$ disseram que homens se exibiram para elas, e $8 \%$ foram estupradas. A região Centro-Oeste é onde as mulheres mais sofreram assédio nas ruas, com $92 \%$ de incidência. Em seguida, vêm Norte (88\%), Nordeste e Sudeste (86\%), e Sul (85\%).

No levantamento, as mulheres foram questionadas sobre em quais situações elas sentiram mais medo de serem assediadas. $70 \%$ responderam que ao andar pelas ruas, $69 \%$ ao sair ou chegar em casa depois que escurece e $68 \%$ no transporte público.

O JC Trânsito é o maior portal de trânsito de Pernambuco e teve como notícia que mais repercutiu em 2015 assédio em coletivos. Ainda em 2015, o mesmo Portal realizou uma matéria onde entrevista vítimas e mostra a problemática entorno da não denúncia sobre os casos de assédio. $\mathrm{O}$ alto índice de silêncio das vítimas traz a reflexão de que o gargalo não está na autodefesa, mas na capacidade de se reconhecer enquanto vítima e fazer a denúncia, já que são a todo momento desencorajadas. Como não são denunciados, estupradores se valem do clima de impunidade. Esse clima não viria somente de falha no sistema judicial, mas também da cultura que estimula o silêncio e culpa duplamente as vítimas pela violência sofrida.

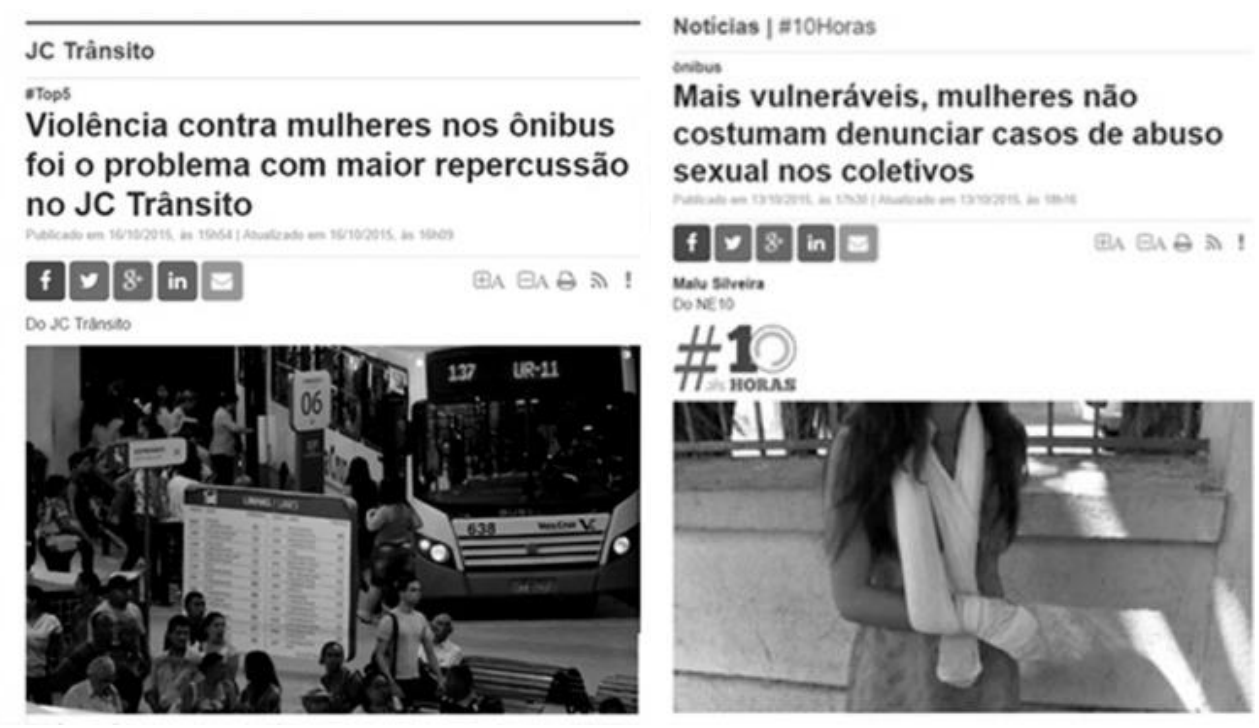

Figura 1. Prints das matérias do Portal JC Trânsito

Os dados estatísticos levantados no estudo, assim como as matérias com relato de vítimas corroboram o comprometimento da mobilidade urbana para as mulheres como impeditivo de desenvolvimento social. Elas têm diariamente o direito de ir e vir negado, restando-lhes duas opções: viver à margem da sociedade ou se arriscar nos caminhos diários e viver à mercê da violência urbana. 


\section{Sororidade Ciberfeminista}

Filas, tumulto, aperto e sufoco. Transporte público, fluxo, corpo vulnerável, disponível, online. Munidas de aparelhos digitais, cada mulher torna-se um alvo móvel. O último senso publicado pela Agência Nacional de Telecomunicações (ANATEL) mostra que o Brasil registrou, em maio de 2015, 284,15 milhões de linhas móveis ativas com densidade de distribuição de 139,16 acessos por 100 habitantes.

A articulação com outras desenvolvedoras a partir do grupo Women Who Code Recife, na rede social Facebook, deu início ao desenvolvimento da rede Nina. A rede visa empoderar as mulheres através de um aplicativo que denuncie tipos de violência que estas sofrem dentro dos espaços públicos, com recorte inicial para transportes públicos. A mulher passa a ter o poder de transformar, em poucos cliques, o seu celular em um "canivete eletrônico" - termo introduzido por Jenkins (2009) - de mapeamento de violência e sororidade ${ }^{3}$. Ao fazer a denúncia ativa-se uma rede de apoio de outros usuários Nina próximos à vítima.

(...) Floss (free libre open source software) para a expansão das redes digitais. Trata-se de comunidades de hackers que desenvolvem programas de computador com o código fonte aberto e com licenças de propriedade permissivas que permitem usar, copiar, estudar completamente, melhorar e distribuir as mudanças realizadas no software. O código-fonte de um software contém as rotinas lógicas detalhadamente encadeadas, escritas em uma linguagem de programação, mostrando tudo que o programa realiza. O códigofonte, uma vez transformado em linguagem de máquina, torna-se um código executável. De posse do código-fonte é possível conhecer, alterar e melhorar o software. Todavia, isso não é possível de posse somente do código executável, pois ele converteu o código-fonte em binário, em um conjunto de zeros e uns, que não podem ser entendidos pelos programadores a não ser que realizem um complexo processo de engenharia reversa. (SILVEIRA, 2010, p. 35).

A construção do aplicativo faz-se híbrido por motivos de não haver necessidade de equipes com conhecimento específicos em desenvolvimento mobile para iOS, Android e Windows, o que, teoricamente, requer pouco tempo e menos custos por recursos. Tendo em vista que as integrantes do grupo possuem conhecimentos em tecnologias Web como CSS, HTML e Java Script, optou-se por utilizar o Ionic. O Ionic Framework é um $S D K^{4}$ de código aberto que permite aos desenvolvedores criar aplicativos móveis de alta qualidade e de alto desempenho usando tecnologias web familiares (HTML, CSS e JavaScript). O aplicativo foi desenvolvido na versão 1.7 do Ionic, porém, devido o lançamento da v.3, mais recente, pretende-se migrar o que se tem do projeto para a nova versão, utilizando o Angular $4^{5}$ desenvolvido por uma parceria

\footnotetext{
${ }^{3}$. Sororidade é a união e aliança entre mulheres, baseado na empatia e companheirismo, em busca de alcançar objetivos em comum. Fonte: http://migre.me/vnYU5

4 SDK é a sigla para Software Development Kit (ou Software Developers Kit - pacote de desenvolvimento de software). É esse pacote que permite à programadores elaborarem aplicativos para rodarem em uma plataforma específica.

5 É um framework JavaScript open source, mantido pelo Google, que auxilia na execução de single-page applications. Seu objetivo é aumentar aplicativos que podem ser acessados por um navegador web, foi
} 
entre a Google e a Microsoft com a linguagem TypeScript ${ }^{6}$. O Ionic na versão 3 foi atualizado para ser compatível com Angular 4.0.0. A atualização apresenta novos recursos, componente de interface de usuário personalizados e Apache Cordova ${ }^{7}$ que ajuda desenvolvedores a criar aplicativos móveis híbridos e também com suporte para aplicativos desktop.

Depois do primeiro desenvolvimento de códigos estável, a equipe deve ser mantida para manutenção do projeto, porém, os integrantes têm como objetivo transformar o Nina em uma plataforma open source para que as pessoas possam estudálo. Com isso, muitos usuários acabam incrementando o software com funcionalidades extras ou até aplicando consertos de bugs que possam ocorrer. Desta forma, as alterações que são de interesse comum são compartilhadas para todos os usuários e usuárias quando o projeto, através do Team, lança uma nova versão estável, e o mesmo tende a crescer exponencialmente tornando-se autossustentável.

\section{Referências bibliográficas}

Castells, Manuel. (2003) "A Galáxia da Internet: Reflexões sobre a internet, os Negócios e a Sociedade", http://migre.me/wkoT7. Acesso em: 30 de outubro de 2016.

Castells, Manuel. (2009) "Comunicación y poder", http://migre.me/wkoZZ. Acesso em: 30 de outubro de 2016.

Jenkins, Henry. (2009). “Cultura da Convergência”. Pág. 28 - 30. Aleph.

Levy, S. (2003) "Hackers - Heroes of the computer revolution", classes.visitsteve.com/hacking/wp-content/Steven-Levy-Hackers-ch1+2.pdf. Acesso em: 30 de out. de 2016.

Martins, B. C. (2006) “Cooperação e Livre fluxo da informação. A influência da Cultura Hacker na Definição dos Padrões da Comunicação Mediada por Computador", http://migre.me/wkujp. Acesso em: 29 de outubro de 2016.

Silveira, Sérgio Amadeu. (2010) "Ciberativismo, cultura hacker e o individualismo colaborativo”, http://migre.me/wkqdc. Pág. 35. Acesso em: 03 de agosto de 2016.

construído sob o padrão model-view-view-model (MVVM), em um esforço para facilitar tanto o desenvolvimento quanto o teste dos aplicativos.

6 TypeScript é uma linguagem para desenvolvimento JavaScript em larga escala. Com TypeScript podemos escrever código utilizando uma estrutura fortemente tipada e ter este código compilado para JavaScript puro. Qualquer navegador. Qualquer host.

7 O Apache Cordova oferece um grupo de APIs que permitem desenvolver uma aplicação com HTML, CSS e JavaScript encapsulada como aplicação móvel nativa. A aplicação é executada no dispositivo móvel e pode acessar as funções nativas do dispositivo, como GPS ou câmera. 